\title{
Assessment and Intervention with Patients with Severe Disorders of Consciousness
}

\author{
Giulio E. Lancioni ${ }^{1}$ • Andrea Bosco ${ }^{1}$ - Mark F. O'Reilly ${ }^{2} \cdot$ Jeff Sigafoos $^{3}$ • \\ Marta Olivetti Belardinelli ${ }^{4}$
}

Published online: 31 May 2017

(C) Springer International Publishing 2017

\section{Introduction}

Much attention has been devoted to assessment and intervention with patients with disorders of consciousness (i.e., patients whose consciousness is affected by damage to the brain) (Bodien and Giacino 2016; Giacino et al. 2014; Gosseries et al. 2016; Laureys et al. 2006; Lopez-Rolon 2017; Stokes et al. 2016). Regarding assessment, the main viewpoint in recent literature underlines the importance of reliably determining the patients' state of functioning (whether they are in a vegetative state or in a minimally conscious state) and suggests a variety of assessment tools that might be suitable for that purpose (Demertzi et al. 2015; Fingelkurts et al. 2016; Fins 2016; Lancioni et al. 2014a). An alternative viewpoint on the issue doubts the dichotomy between vegetative state (or Unresponsive Wakefulness Syndrome) and minimally conscious state and, in light of that, any specific needs to refine the assessment strategies and determine the dividing lines between those two states (Gosseries et al. 2014; Liberati et al. 2014).

Regarding intervention, multiple procedures (e.g., environmental and brain stimulation) have been advocated to improve the condition of patients with disorders of consciousness (Di Stefano et al. 2012; Georgiopoulos et al. 2010; Lancioni et al.

Giulio E. Lancioni

giulio.lancioni@uniba.it

1 Department of Neuroscience and Sense Organs, University of Bari, Corso Italia 23, 70121 Bari, Italy

2 University of Texas at Austin, Austin, TX, USA

3 Victoria University of Wellington, Wellington, New Zealand

4 Sapienza University of Rome, Rome, Italy 2014b; Lotze et al. 2011; Pape et al. 2015). Those procedures indicate diverse types of emphasis and theoretical backgrounds, which have clear implications (a) for the role of the assessment (for deciding whether the functioning level of the patient should be determined prior to the intervention) and (b) for the role of the patient within the intervention program set up for him or her (Hauger et al. 2015, 2017; Lancioni et al. 2014a). The goal of this paper is to reflect on both assessment and intervention by providing a brief account of main assessment and intervention procedures, drawing general considerations about their usability and potential, and envisaging possible lines of progress in those areas.

\section{Assessment Procedures}

Main assessment tools for determining an individual's functioning state include behavioral scales, neurophysiological strategies, neuroimaging techniques, and learning test strategies. Typically, more than one tool is used for the assessment. Behavioral scales are perhaps the most accessible and most frequently used assessment tools (Boly 2011; Lechinger et al. 2013; Seel et al. 2010). The Coma Recovery Scale-Revised (CRS-R) is considered to be the most dependable scale for identifying sensory and communication expressions or responses to objects that serve to determine the patient's level of functioning (Boly 2011; Bosco et al. 2010; Bruno et al. 2011; Doig and Lane-Brown 2012; Godbolt et al. 2012; Kalmar and Giacino 2005; La Porta et al. 2013; Schnakers et al. 2009; Seel et al. 2010; Shiel et al. 2000). Problems with this scale (and similar scales) are likely to arise when patients do not possess the hand and head responses relevant for some of the scale items and/or are unable to comprehend verbal instructions (Bosco et al. 2009; Di Perri et al. 2016; 
Lancioni et al. 2014a; Owen and Coleman 2008; SchmitterEdgecombe 2006).

Neurophysiological strategies for investigating eventrelated brain potentials (P300 and mismatch negativity) are also commonly used with patients with severe disorders of consciousness (Cavinato et al. 2009; Höller et al. 2011; King et al. 2013; Lehembre et al. 2012; Perrin et al. 2006; Qin et al. 2008). Evidence of $P 300$ responses and mismatch negativity has been generally considered a signal of the patient's potential abilities in terms of awareness/consciousness with relevant implications for his or her recovery process (Blume et al. 2015; Fischer et al. 2010; Lugo et al. 2016; Risetti et al. 2013; Vanhaudenhuyse et al. 2008; Wijnen et al. 2007). In a partial revision of this view, recent literature cautions about the reliability and predictive value of P300 and mismatch negativity (Hauger et al. 2017) and emphasizes the advantages of using multiple/different measures to improve the representativeness of the findings (Sergent et al. 2017).

Neuroimaging techniques, such as functional magnetic resonance imaging (fMRI), can help identify potential abilities even in cases with minimal (or no apparent) responsiveness (Bodart et al. 2013; Coleman and Pickard 2011; Harrison and Connolly 2013; Monti 2012; Owen 2013; Owen and Coleman 2008). Indeed, the use of those techniques has allowed researchers to reach important diagnostic conclusions (e.g., Blume et al. 2015; Monti et al. 2010; Owen et al. 2006). Notwithstanding the power of these techniques, their application remains a difficult methodological and practical challenge in most medical and care or rehabilitation contexts and might also lead to unreliable results in patients who have problems focusing on specific assessment stimuli or following verbal instructions (Bodien and Giacino 2016; Edlow et al. 2013; Harrison and Connolly 2013; Mashour and Avidan 2013; Vul and Pashler 2012). A similarly powerful and complex alternative to fMRI in this assessment area is positron emission tomography (PET) (Giacino et al. 2014; Rosanova et al. 2012; Stender et al. 2014, 2016).

Learning test strategies introduced fairly recently (Juan et al. 2016; Kim et al. 2012; Lancioni et al. 2009b, 2014a; Monti 2012) can be of two types. One is based on classical learning principles (Pierce and Cheney 2008) and is aimed at assessing the patients' ability to associate pairs of stimuli (Bekinschtein et al. 2009). The other is based on operant learning principles (Pierce and Cheney 2008) and is aimed at assessing the patients' ability to associate a response with the stimulation that follows it (Lancioni et al. 2009a, 2014a). Signs of learning within either strategy (i.e., the achievement of an association between events) may be taken to suggest a non-reflective level of phenomenal consciousness, and thus to support a diagnosis of minimally conscious state (Bekinschtein et al. 2009; Bosco et al. 2009, 2010; Lancioni et al. 2009b, 2014a). Learning test strategies may be seen as critically relevant for patients who have only basic/minimal responses, such as eyelid or lip movements (i.e., patients who are likely to have problems with the CRS-R). Adaptations of the learning test strategy based on operant learning principles may also be employed as intervention programs and help fostering an active role for the patient (Bagnato et al. 2013; Lancioni et al. 2012; Machado and Korein 2009).

\section{Intervention Procedures}

Main intervention procedures for persons with disorders of consciousness include various forms of environmental stimulation, transcranial magnetic stimulation (TMS) or transcranial direct current stimulation (tDCS), deep brain stimulation, and learning-based intervention programs (i.e., programs constituting practical adaptations of the aforementioned learning test strategies) (Daveson 2010; Lancioni et al. 2014a; Magee et al. 2016; Pape et al. 2009, 2012; Piccione et al. 2011; Schnakers et al. 2016).

Environmental stimulation is normally arranged and controlled by caregivers/therapists in charge of the patients and represents the most frequently used intervention approach (Abbate et al. 2014; Sullivan et al. 2017). In its basic form, this approach involves the presentation of simple, daily stimulus events such as music and verbal inputs during specific periods of time (Daveson 2010; Georgiopoulos et al. 2010; Giacino 1996; Hirschberg and Giacino 2011). In its more elaborate forms, this approach involves specific daily sessions with the presentation of intensive multisensory stimulation, a physically and verbally guided manipulation of relevant daily objects or exposure to emotional and autobiographical stories (e.g., Di Stefano et al. 2012; Pape et al. 2015). The most basic forms of stimulation are considered unlikely to have a significant impact on the patients' levels of attention and direct involvement with the context or their long-term recovery prospects (Abbate et al. 2014; Lancioni et al. 2014b; Lombardi et al. 2002). The intensive/elaborate and emotionally charged forms of stimulation are considered more likely to have positive effects on the patients' behavior and recovery process (Di Stefano et al. 2012; Lotze et al. 2011; Pape et al. 2015).

The use of TMS or tDCS represents a fairly common approach, whose implementation does not require any specific/ direct involvement on the part of the patient (Chervyakov et al. 2015; Guerra et al. 2014; Pisani et al. 2015). While general support is available for this approach, the studies assessing its impact with patients with disorders of consciousness seem to suggest some caution. For example, Pape et al. (2009), Piccione et al. (2011), and Manganotti et al. (2013) reported differing results as to the effectiveness of repeated TMS in fostering the patients' arousal and awareness. Angelakis et al. (2014), Naro et al. (2015, 2016), and Thibaut et al. $(2014,2017)$ reported promising effects of tDCS, but these effects were not necessarily robust or 
consistent across patients and were related to different types of measures (Lefaucheur et al. 2017).

The studies reporting on deep brain stimulation (i.e., electrical stimulation of the thalamus through implanted electrodes) have stressed that this approach might prove quite relevant in terms of its overall impact, that is, in terms of increase in patients' alertness, awareness, and general responsiveness. Even so, great caution is required with respect to the use of this approach, as it remains an experimental, hospitalbased methodology, which has been subject to limited research evaluation and presents serious medical risks connected to the implantation and maintenance of the electrodes (Giacino et al. 2012; Guerra et al. 2014; Schiff et al. 2007, 2009; Yamamoto et al. 2013).

Learning-based intervention programs are largely different from the aforementioned intervention approaches. Indeed, these programs are designed to monitor the patients' responding and ensure that such responding becomes an effective means to manage stimulation control and/or social interaction requests independently of external assistance (Lancioni et al. 2014a, b, c, 2015; Wallace and Bradshaw 2011). In practice, the objective of these programs is to help the patients acquire an active role characterized by selfdetermination and positive behavioral engagement. Promoting such a role affords an opportunity to grow rather than a simple increase in stimulation input (Lancioni et al. 2014c; McNamee et al. 2012; Müller-Patz et al. 2013).

The first three approaches mentioned above (i.e., environmental stimulation arranged/mediated by a therapist, TMS or tDCS, and deep brain stimulation) are deemed applicable with patients in a vegetative state as well as patients in a minimally conscious state. The approach based on learning principles, on the other hand, can be considered functional/specific for patients in a minimally conscious state, that is, for patients who can learn the relationship between their responding and environmental events (Lancioni et al. 2014a, 2015). This approach allows them to plan their responding and make it meaningful, with consequent improvements in alertness/attention (Lancioni et al. 2014b, c).

Following the aforementioned statements about the different approaches, it could be argued that the adoption of any of the first three does not necessarily require preliminary assessment of the patient's functioning state. The adoption of the last approach, by contrast, relies on and assumes the presence of a minimally conscious state that needs to be previously ascertained.

\section{Discussion}

Two closing considerations could be formulated with regard to assessment. First, using supplements to (corrections of) the behavioral scales might be viewed as a practically relevant initiative to overcome the limitations of the scales and increase diagnostic accuracy. The aforementioned learning test strategies and the complementary motor behavior evaluation tool recently described by Pignat et al. (2016) could be interpreted as examples of those supplements/corrections (Di Perri et al. 2016; Lancioni et al. 2014a; Monti 2012). Second, repeating the assessment over time and using combinations of behavioral and electrophysiological or neuroimaging procedures for such an assessment would constitute important cautionary conditions to curb the risks connected with individual fluctuations and reduce misdiagnosis (Cortese et al. 2015; Dolce et al. 2015; Gilutz et al. 2015).

Two closing considerations could also be formulated with regard to intervention. First, additional data would be essential to determine the real impact of the different intervention procedures and the reliability/stability of such impact across patients. Second, comparisons between procedures could be critically important to establish their relative effects on a number of dimensions. For example, one could compare common programs of environmental stimulation with learning-based intervention programs on measures such as attention and alertness. To this end, one could gather data on eye-opening time, orienting, and head movements or on heart-rate variability under the different conditions (Dolce et al. 2015; Lancioni et al. 2014c; Riganello et al. 2013).

In conclusion, it could be argued that the assessment and intervention procedures available represent a massive resource for any professional working with patients with disorders of consciousness, but do not always ensure a satisfactory outcome due to limitations in applicability/reliability or general impact. New research efforts would need to (a) determine ways to make the assessment practically affordable and dependable (e.g., by envisaging supplements to or combinations of what is available; see above) and (b) clarify how best to measure the impact and implications of the intervention strategies so as to reach a new level of knowledge and advance in this area.

Authors' Contributions GEL conceived and wrote the paper, and AB, MFO'R, JS, and MOB contributed to the writing and editing of the paper.

\section{Compliance with Ethical Standards}

Conflict of Interest The authors declare that they have no conflict of interest.

\section{References}

Abbate, C., Trimarchi, P. D., Basile, I., Mazzucchi, A., \& Devalle, G. (2014). Sensory stimulation for patients with disorders of consciousness: from stimulation to rehabilitation. Frontiers in Human Neuroscience, 8, 616. doi:10.3389/fnhum.2014.00616. 
Angelakis, E., Liouta, E., Andreadis, N., Korfias, P., Stranialis, G., \& Sakas, D. E. (2014). Transcranial direct current stimulation (tDCS) effects in disorders of consciousness. Archieves of Physical Medicine and Rehabilitation, 95, 283-289. doi:10.1016/j.apmr. 2013.09.002.

Bagnato, S., Boccagni, C., Sant'Angelo, A., Fingelkurts, A. A., Fingelkurts, A. A., \& Galardi, G. (2013). Emerging from an unresponsive wakefulness syndrome: brain plasticity has to cross a threshold level. Neuroscience \& Behavioral Reviews, 37(Pt 2), 2721-2736. doi:10.1016/j.neurobiorev.2013.09.007.

Bekinschtein, T. A., Shalom, D. E., Forcato, C., Herrera, M., Coleman, M. R., Manes, F. F., et al. (2009). Classical conditioning in the vegetative and minimally conscious state. Nature Neuroscience, 12, 1343-1349. doi:10.1038/nn.2391.

Blume, C., Del Giudice, R., Wislowska, M., Lechinger, J., \& Schabus, M. (2015). Across the consciousness continuum - from unresponsive wakefulness to sleep. Frontiers in Human Neuroscience, 9, 105. doi:10.3389/fnhum.2015.00105.

Bodart, O., Laureys, S., \& Gosseries, O. (2013). Coma and consciousness: scientific advances and practical considerations for clinicians. Seminars in Neurolology, 33, 83-90. doi:10.1055/s-0033-1348965.

Bodien, Y. G., \& Giacino, J. T. (2016). Challenges and pitfalls associated with diagnostic and prognostic applications of functional neuroimaging in disorders of consciousness. The Open Neuroimaging Journal, 10(Suppl-1, M2), 23-31. doi:10.2174/1874440001610010023.

Boly, M. (2011). Measuring the fading consciousness in the human brain. Current Opinion in Neurology, 24, 394-400. doi:10.1097/WCO. 0b013e328347da94.

Bosco, A., Lancioni, G. E., Olivetti Belardinelli, M., Singh, N. N., O'Reilly, M. F., \& Sigafoos, J. (2009). Learning as a possible sign of non-reflective consciousness in persons with a diagnosis of vegetative state and pervasive motor disabilities. Cognitive Processing, 10, 355-359. doi:10.1007/s10339-009-0334-3.

Bosco, A., Lancioni, G. E., Olivetti Belardinelli, M., Singh, N. N., O'Reilly, M. F., \& Sigafoos, J. (2010). Vegetative state: efforts to curb misdiagnosis. Cognitive Processing, 11, 87-90. doi:10.1007/ s10339-009-0355-y.

Bruno, M. A., Vanhaudenhuyse, A., Thibaut, A., Moonen, G., \& Laureys, S. (2011). From unresponsive wakefulness to minimally conscious PLUS and functional locked-in syndromes: recent advances in our understanding of disorders of consciousness. Journal of Neurology, 258, 1373-1384. doi:10.1007/s00415-011-6114-x.

Cavinato, M., Freo, U., Ori, C., Zorzi, M., Tonin, P., Piccione, F., et al. (2009). Post-acute P300 predicts recovery of consciousness from traumatic vegetative state. Brain Injury, 23, 973-980. doi:10.3109/ 02699050903373493.

Chervyakov, A. V., Chernyavsky, A. Y., Sinitsyn, D. O., \& Piradov, M. A. (2015). Possible mechanisms underlying the therapeutic effects of transcranial magnetic stimulation. Frontiers in Human Neuroscience, 9, 303. doi:10.3389/fnhum.2015.00303.

Coleman, M. R., \& Pickard, J. D. (2011). Detecting residual cognitive function in disorders of consciousness. Advances and Technical Standards in Neurosurgery, 36, 3-16. doi:10.1007/978-3-70910179-7 1.

Cortese, M. D., Riganello, F., Arcuri, F., Pugliese, M. E., Lucca, L. F., Dolce, G., et al. (2015). Coma recovery scale-r: variability in the disorder of consciousness. BMC Neurology, 15, 186. doi:10.1186/ s12883-015-0455-5.

Daveson, B. (2010). An audit about music therapy assessments and recommendations for adult patients suspected to be in a low awareness state. Journal of Music Therapy, 47, 408-422.

Demertzi, A., Antonopoulos, G., Heine, L., Voss, H. U., Crone, J. S., de Los Angeles, C., et al. (2015). Intrinsic functional connectivity differentiates minimally conscious from unresponsive patients. Brain, 138, 2619-2631. doi:10.1093/brain/awv169.
Di Perri, C., Thibaut, A., Heine, L., Annen, J., \& Laureys, S. (2016). Towards new methods of diagnosis in disorders of consciousness: authors' reply. Lancet Neurology, 15, 1115-1116. doi:10.1016/ S1474-4422(16)30205-8.

Di Stefano, C., Cortesi, A., Masotti, S., Simoncini, L., \& Piperno, R. (2012). Increased behavioural responsiveness with complex stimulation in VS and MCS: preliminary results. Brain Injury, 26, 1250 1256. doi:10.3109/02699052.2012.667588.

Doig, E. J., \& Lane-Brown, A. T. (2012). Responsiveness of instruments to assess disorders of consciousness: a literature review. Brain Impairment, 13, 285-315. doi:10.1017/BrImp.2012.29.

Dolce, G., Arcuri, F., Carozzo, S., Cortese, M. D., Greco, P., Lucca, L. F., et al. (2015). Care and neurorehabilitation in the disorder of consciousness: a model in progress. Scientific World Journal. doi:10. 1155/2015/463829.

Edlow, B. L., Giacino, J. T., \& Wu, O. (2013). Functional MRI and outcome in traumatic coma. Current Neurology and Neuroscience Reports, 13(9). doi:10.1007/s11910-013-0375-y.

Fingelkurts, A. A., Fingelkurts, A. A., Bagnato, S., Boccagni, C., \& Galardi, G. (2016). Long-term (six years) clinical outcome discrimination of patients in the vegetative state could be achieved based on the operational architectonics EEG analysis: a pilot feasibility study. The Open Neuroimaging Journal, 10, 69-79. doi:10.2174/ 1874440001610010069.

Fins, J. J. (2016). Neuroethics and disorders of consciousness: discerning brain states in clinical practice and research. AMA Journal of Ethics, 18, 1182-1191. doi:10.1001/journalofethics.2016.

Fischer, C., Luaute, J., \& Morlet, D. (2010). Event-related potentials (MMN and novelty P3) in permanent vegetative or minimally conscious states. Clinical Neurophysiology, 121, 1032-1042. doi:10. 1016/j.clinph.2010.02.005.

Georgiopoulos, M., Katsakiori, P., Kefalopoulou, Z., Ellul, J., Chroni, E., \& Constantoyannis, C. (2010). Vegetative state and minimally conscious state: a review of the therapeutic interventions. Stereotactic and Functional Neurosurgery, 88, 199-207.

Giacino, J. T. (1996). Sensory stimulation: theoretical perspectives and the evidence for effectiveness. NeuroRehabilitation, 6, 69-78. doi: 10.3233/NRE-1996-6108.

Giacino, J., Fins, J. J., Machado, A., \& Schiff, N. D. (2012). Central thalamic deep brain stimulation to promote recovery from chronic posttraumatic minimally conscious state: challenges and opportunities. Neuromodulation, 15, 339-349. doi:10.1111/j.1525-1403. 2012.00458.x.

Giacino, J. T., Fins, J. J., Laureys, S., \& Schiff, N. D. (2014). Disorders of consciousness after acquired brain injury: the state of the science. Nature Review Neurology, 10, 99-114. doi:10.1038/nrneurol.2013. 279.

Gilutz, Y., Lazary, A., Karpin, H., Vatine, J. J., Misha, T., Fortinsky, H., et al. (2015). Detailed behavioral assessment promotes accurate diagnosis in patients with disorders of consciousness. Frontiers in Human Neuroscience, 9, 87. doi:10.3389/fnhum.2015.00087.

Godbolt, A. K., Stenson, S., Winberg, M., \& Tengvar, C. (2012). Disorders of consciousness: preliminary data supports added value of extended behavioral assessment. Brain Injury, 26, 188-193. doi: 10.3109/02699052.2011.648708.

Gosseries, O., Thibaut, A., Boly, M., Rosanova, M., Massimini, M., \& Laureys, S. (2014). Assessing consciousness in coma and related states using transcranial magnetic stimulation combined with electroencephalography. Annales Francaises d'Anesthesie et de Reanimation, 33, 65-71. doi:10.1016/j.Annfar.2013.11.002.

Gosseries, O., Pistoia, F., Charland-Verville, V., Carolei, A., Sacco, S., \& Laureys, S. (2016). The role of neuroimaging techniques in establishing diagnosis, prognosis and therapy in disorders of consciousness. Open Neuroimaging Journal, 10(Suppl-1, M2), 52-68. doi:10. 2174/1874440001610010052. 
Guerra, A., Costantini, E. M., Maatta, S., Ponzo, D., \& Ferreri, F. (2014). Disorders of consciousness and electrophysiological treatment strategies: a review of the literature and new perspectives. Current Pharmaceutical Design, 20, 4248-4267. doi:10.2174/ 13816128113196660648.

Harrison, A. H., \& Connolly, J. F. (2013). Finding a way in: a review and practical evaluation of fMRI and EEG for detection and assessment in disorders of consciousness. Neuroscience and Biobehavioral Reviews, 37, 1403-1419. doi:10.1016/j.neubiorev.2013.05.004.

Hauger, S. L., Schnakers, C., Andersson, S., Becker, F., Moberget, T., Giacino, J. T., et al. (2015). Neurophysiological indicators of residual cognitive capacity in the minimally conscious state. Behavioral Neurology, 2015, 145913. doi:10.1155/2015/145913.

Hauger, S. L., Schanke, A. K., Andersson, S., Chatelle, C., Schnakers, C., \& LØvstad, M. (2017). The clinical diagnostic utility of electrophysiological techniques in assessment of patients with disorders of consciousness following acquired brain injury: a systematic review. The Journal of Head Trauma Rehabilitation. doi:10.1097/HTR. 0000000000000267.

Hirschberg, R., \& Giacino, J. T. (2011). The vegetative and minimally conscious states: diagnosis, prognosis and treatment. Neurologic Clinics, 29, 773-786. doi:10.1016/j.ncl.2011.07.009.

Höller, Y., Bergmann, J., Kronbichler, M., Crone, J. S., Schmid, E. V., Golaszewski, S., et al. (2011). Preserved oscillatory response but lack of mismatch negativity in patients with disorders of consciousness. Clinical Neurophysiology, 122, 1744-1754. doi:10.1016/j. clinph.2011.02.009.

Juan, E., Nguepnjo Nguissi, N. A., Tzovara, A., Viceic, D., Rusca, M., Oddo, M., et al. (2016). Evidence of trace conditioning in comatose patients revealed by the reactivation of EEG responses to alerting sounds. NeuroImage, 141, 530-541. doi:10.1016/j.neuroimage. 2016.07.039.

Kalmar, K., \& Giacino, J. T. (2005). The JFK Coma Recovery Scalerevised. Neuropsychological Rehabilitation, 15, 454-460. doi:10. 1080/09602010443000425.

Kim, E. J., Park, J. M., Kim, W. H., Lee, K. L., Kim, H. N., Lee, K. E., et al. (2012). A learning set up for detecting minimally conscious state (MCS). Annals of Rehabilitation Medicine, 36, 428-431. doi: 10.5535/arm.2012.36.3.428.

King, J. R., Faugeras, F., Gramfort, A., Schurger, A., El Karoul, I., Sitt, J. D., et al. (2013). Single-trial decoding of auditory novelty responses facilitates the detection of residual consciousness. NeuroImage, 83C, 726-738. doi:10.1016/j.neuroimage.2013.07.013.

La Porta, F., Caselli, S., Ianes, A. B., Cameli, O., Lino, M., Piperno, R., et al. (2013). Can we scientifically and reliably measure the level of consciousness in vegetative and minimally conscious states? Rasch analysis of the coma recovery scale-revised. Archives of Physical Medicine and Rehabilitation, 94, 527-535. doi:10.1016/j.apmr. 2012. 09.035 .

Lancioni, G. E., O'Reilly, M. F., Singh, N. N., Buonocunto, F., Sacco, V., Colonna, F., et al. (2009a). Evaluation of technology-assisted learning setups for undertaking assessment and providing intervention to persons with a diagnosis of vegetative state. Developmental Neurorehabilitation, 12, 411-420. doi:10.3109/17518420903200581.

Lancioni, G. E., Singh, N. N., O'Reilly, M. F., Sigafoos, J., Buonocunto, F., Sacco, V., et al. (2009b). A technology-assisted learning setup as assessment supplement for three persons with a diagnosis of postcoma vegetative state and pervasive motor impairment. Research in Developmental Disabilities, 30, 1034-1043. doi:10.1016/j.ridd. 2009.02.006.

Lancioni, G. E., Singh, N. N., O’Reilly, M. F., Sigafoos, J., Amenduni, M. T., Navarro, J., et al. (2012). Microswitch technology and contingent stimulation to promote adaptive engagement in persons with minimally conscious state: a case evaluation. Cognitive Processing, 13, 133-137. doi:10.1007/s10339-011-0428-6.
Lancioni, G. E., Bosco, A., Olivetti Belardinelli, M., Singh, N. N., O'Reilly, M. F., Sigafoos, J., et al. (2014a). Assessing learning as a possible sign of consciousness in post-coma persons with minimal responsiveness. Frontiers in Human Neuroscience, 8, 25. doi:10. 3389/fnhum.2014.00025.

Lancioni, G. E., Bosco, A., Olivetti Belardinelli, M., Singh, N. N., O'Reilly, M. F., Sigafoos, J., et al. (2014b). Technology-based intervention programs to promote stimulation control and communication in post-coma persons with different levels of disability. Frontiers in Human Neuroscience, 8, 48. doi:10.3389/fnhum. 2014.00048.

Lancioni, G. E., Singh, N. N., O'Reilly, M. F., Green, V. A., Buonocunto, F., Sacco, V., et al. (2014c). Microswitch-aided programs with contingent stimulation versus general stimulation programs for postcoma persons with multiple disabilities. Developmental Neurorehabilitation, 17, 251-258. doi:10.3109/17518423.2013. 793751.

Lancioni, G. E., Singh, N. N., O’Reilly, M. F., Sigafoos, J., D’Amico, F., Buonocunto, F., et al. (2015). Assistive technology to help persons in a minimally conscious state develop responding and stimulation control: performance assessment and social rating. NeuroRehabilitation, 37, 393-403. doi:10.3233/NRE-151269.

Laureys, S., Boly, M., \& Maquet, P. (2006). Tracking the recovery of consciousness from coma. Journal of Clinical Investigation, 116, 1823-1825. doi:10.1172/JCI29172.

Lechinger, J., Bothe, K., Pichler, G., Michitsch, G., Donis, J., Klimesch, W., et al. (2013). CRS-R score in disorders of consciousness is strongly related to spectral EEG at rest. Journal of Neurology, 260, 2348-2356. doi:10.1007/s00415-013-6982-3.

Lefaucheur, J. P., Antal, A., Ayache, S. S., Benninger, D. H., Brunelin, J., Cogiamanian, F., et al. (2017). Evidence-based guidelines on the therapeutic use of transcranial direct current stimulation (tDCS). Clinical Neurophysiology, 128, 56-92. doi:10.1016/j.clinph.2016. 10.087 .

Lehembre, R., Gosseries, O., Lugo, Z., Jedidi, Z., Chatelle, C., Sadzot, B., et al. (2012). Electrophysiological investigations of brain function in coma, vegetative and minimally conscious patients. Archives Italiennes de Biologie, 150, 122-139. doi:10.4449/aib.v150i2.1374.

Liberati, G., Hünefeldt, T., \& Olivetti Belardinelli, M. (2014). Questioning the dichotomy between vegetative state and minimally conscious state: a review of the statistical evidence. Frontiers in Human Neuroscience, 8, 865. doi:10.3389/fnhum.2014.00865.

Lombardi, F., Taricco, M., De Tanti, A., Telaro, E., \& Liberati, A. (2002). Sensory stimulation of brain-injured individuals in coma or vegetative state: results of a Cochrane systematic review. Clinical Rehabilitation, 16, 464-472. doi:10.1191/0269215502cr519oa.

Lopez-Rolon, A. (2017). Severe disorders of consciousness after acquired brain injury: a single-centre long-term follow-up study. NeuroRehabilitation. doi:10.3233/NRE-171438.

Lotze, M., Schertel, K., Birbaumer, N., \& Kotchoubey, B. (2011). A longterm intensive behavioral treatment study in patients with persistent vegetative state or minimally conscious state. Journal of Rehabilitation Medicine, 43, 230-236. doi:10.2340/165019770653.

Lugo, Z. R., Quitadamo, L., Bianchi, L., Pellas, F., Veser, S., Lesenfants, D., et al. (2016). Cognitive processing in non-communicative patients: what can event-related potentials tell us? Frontiers in Human Neuroscience, 10, 569. doi:10.3389/fnhum.2016.00569.

Machado, C., \& Korein, J. (2009). Persistent vegetative and minimally conscious states. Reviews in the Neurosciences, 20, 203-220. doi: 10.1515/REVNEURO.2009.20.3-4.203.

Magee, W. L., Tillman, B., Perrin, F., \& Schnakers, C. (2016). Editorial: music and disorders of consciousness: emerging research, practice and theory. Frontiers in Psychology, 7, 1273. doi:10.3389/fpsyg. 2016.01273 . 
Manganotti, P., Formaggio, E., Storti, S. F., Fiaschi, A., Battistin, L., Tonin, P., et al. (2013). Effect of high-frequency repetitive transcranial magnetic stimulation on brain excitability in severely braininjured patients in minimally conscious or vegetative state. Brain Stimulation, 6, 913-921. doi:10.1016/j.brs.2013.06.006.

Mashour, G. A., \& Avidan, M. S. (2013). Capturing covert consciousness. Lancet, 381, 271-272. doi:10.1016/S0140-6736(13)60094-X.

McNamee, S., Howe, L., Nakase-Richardson, R., \& Peterson, M. (2012). Treatment of disorders of consciousness in the Veterans Health Administration polytrauma centers. The Journal of Head Trauma Rehabilitation, 27, 244-252. doi:10.1097/HTR.0b013e31825e12c8.

Monti, M. M. (2012). Cognition in the vegetative state. Annual Review of Clinical Psychology, 8, 431-454. doi:10.1146/annurev-clinpsy032511-143050.

Monti, M. M., Vanhaudenhuyse, A., Coleman, M. R., Boly, M., Pickard, J. D., Tshibanda, L., et al. (2010). Willful modulation of brain activity in disorders of consciousness. The New England Journal of Medicine, 362, 579-589. doi:10.1056/NEJMoa 0905370.

Müller-Patz, G. R., Pokorny, C., Klobassa, D. S., \& Horki, P. (2013). A single-switch $\mathrm{BCI}$ based on passive and imagined movements: toward restoring communication in minimally conscious patients. International Journal of Neural Systems, 23, 1250037. doi:10. 1142/S0129065712500372.

Naro, A., Calabrò, R. S., Russo, M., Leo, A., Pollicino, P., Quartarone, A., et al. (2015). Can transcranial direct current stimulation be useful in differentiating unresponsive wakefulness syndrome from minimally conscious state patients? Restorative Neurology and Neuroscience, $33,159-176$.

Naro, A., Russo, M., Leo, A., Cannavò, A., Manuli, A., Bramanti, A., et al. (2016). Cortical connectivity modulation induced by cerebellar oscillatory transcranial direct current stimulation in patients with chronic disorders of consciousness: a marker of covert cognition? Clinical Neurophysiology, 127, 1845-1854.

Owen, A. M. (2013). Detecting consciousness: a unique role for neuroimaging. Annual Review of Psychology, 64, 109-133. doi:10.1146/ annurev-psych-113011-143729.

Owen, A. M., \& Coleman, M. R. (2008). Detecting awareness in the vegetative state. Annals of the New York Academy of Sciences, 1129, 130-138. doi:10.1196/annals.1417.018.

Owen, A. M., Coleman, M. R., Boly, M., Davis, M. H., Laureys, S., \& Pickard, J. D. (2006). Detecting awareness in the vegetative state. Science, 313, 1402. doi:10.1126/science.1130197.

Pape, T. L. B., Rosenow, J., Lewis, G., Ahmed, G., Walker, M., Guernon, A., et al. (2009). Repetitive transcranial magnetic stimulationassociated neurobehavioral gains during coma recovery. Brain Stimulation, 2, 22-35. doi:10.1016/j.brs.2008.09.004.

Pape, T. L. B., Rosenow, J. M., Harton, B. S., Patil, V., Guernon, A., Parrish, T., et al. (2012). Preliminary framework for Familiar Auditory Sensory Training (FAST) provided during coma recovery. Journal of Rehabilitation Research and Development, 49, 11371152. doi:10.1682/JRRD.2011.08.0154.

Pape, T. L. B., Rosenow, J., Steiner, M., Parrish, T., Guernon, A., Harton, B., et al. (2015). Placebo-controlled trial of familiar auditory sensory training for acute severe traumatic brain injury: a preliminary report. Neurorehabilitation and Neural Repair, 29, 537-547. doi:10.1177/ 1545968314554626.

Perrin, F., Schnakers, C., Schabus, M., Degueldre, C., Goldman, S., Brédart, S., et al. (2006). Brain response to one's own name in vegetative state, minimally conscious state, and locked-in syndrome. Archives of Neurology, 63, 562-569. doi:10.1001/archneur.63.4. 562.

Piccione, F., Cavinato, M., Manganotti, P., Formaggio, E., Storti, S. F., Battistin, L., et al. (2011). Behavioral and neurophysiological effects of repetitive transcranial magnetic stimulation on the minimally conscious state: a case study. Neurorehabilitation and Neural Repair, 25, 98-102. doi:10.1177/1545968310369802.
Pierce, W. D., \& Cheney, C. D. (2008). Behavior analysis and learning (4th ed.). New York: Psychology Press.

Pignat, J. M., Mauron, E., Jöhr, J., Gilart de Keranflec'h, C., Van De Ville, D., Preti, M. G., et al. (2016). Outcome prediction of consciousness disorders in the acute stage based on the complementary motor behavioural tool. PloS One, 11, e0156882. doi:10.1371/journal. pone. 0156882 .

Pisani, L. R., Naro, A., Leo, A., Aricò, I., Pisani, F., Silvestri, R., et al. (2015). Repetitive transcranial magnetic stimulation induced slow wave activity modification: a possible role in disorders of consciousness differential diagnosis? Consciousness and Cognition, 38. doi: 10.1016/j.concog.2015.09.012.

Qin, P., Di, H., Yan, X., Yu, S., Yu, D., Laureys, S., et al. (2008). Mismatch negativity to the patient's own name in chronic disorders of consciousness. Neuroscience Letters, 448, 24-28. doi:10.1016/j. neulet.2008.10.029.

Riganello, F., Cortese, M. D., Dolce, G., \& Sannita, W. G. (2013). Visual pursuit response in the severe disorder of consciousness: modulation by the central automatic system and a predictive model. $B M C$ Neurology, 13, 164. doi:10.1186/1471-2377-13-164.

Risetti, M., Formisano, R., Toppi, J., Quitadamo, L. R., Bianchi, L., Astolfi, L., et al. (2013). On ERPs detection in disorders of consciousness rehabilitation. Frontiers in Human Neuroscience, 7, 775. doi:10.3389/fnhum.2013.00775.

Rosanova, M., Gosseries, O., Casarotto, S., Boly, M., Casali, A. G., Bruno, M. A., et al. (2012). Recovery of cortical effective connectivity and recovery of consciousness in vegetative patients. Brain, 135, 1308-1320. doi:10.1093/brain/awr340.

Schiff, N. D., Giacino, J. T., Kalmar, K., Victor, J. D., Baker, K., Gerber, M., et al. (2007). Behavioural improvements with thalamic stimulation after severe traumatic brain injury. Nature, 448, 600-603 [Published correction: Nature, 452, 120]. doi:10.1038/nature06041.

Schiff, N. D., Giacino, J. T., \& Fins, J. J. (2009). Deep brain stimulation, neuroethics, and the minimally conscious state. Archives of Neurology, 66, 697-702. doi:10.1001/archneurol.2009.79.

Schmitter-Edgecombe, M. (2006). Implications of basic science research for brain injury rehabilitation. The Journal of Head Trauma Rehabilitation, 21, 131-141.

Schnakers, C., Vanhaudenhuyse, A., Giacino, J., Ventura, M., Boly, M., Majerus, S., et al. (2009). Diagnostic accuracy of the vegetative and minimally conscious state: clinical consensus versus standardized neurobehavioral assessment. BMC Neurology, 9, 35. doi:10.1186/ 1471-2377-9-35.

Schnakers, C., Magee, W. L., \& Harris, B. (2016). Sensory stimulation and music therapy programs for treating disorders of consciousness. Frontiers in Psychology, 7, 297. doi:10.3389/fpsyg.2016.00297.

Seel, R. T., Sherer, M., Whyte, J., Katz, D. I., Giacino, J. T., Rosembaum, A. M., et al. (2010). Assessment scales for disorders of consciousness: evidence-based recommendations for clinical practice and research. Archives of Physical Medicine and Rehabilitation, 91, 17951813. doi:10.1016/j.apmr.2010.07.218.

Sergent, C., Faugerars, F., Rohaut, B., Perrin, F., Valente, M., TallonBaudry, C., Cohen, L., \& Naccache, L. (2017). Multidemensional cognitive evaluation of patients with disorders of consciousness using EEG: a proof of concept study. Neurolmage: Clinical, 13, 455-469. doi:10.1016/j.nicl.2016.12.004.

Shiel, A., Horn, S., Wilson, B. A., McLellan, D. L., Watson, M., \& Campbell, M. (2000). The Wessex head injury matrix main scale: a preliminary report on a scale to assess and monitor patients' recovery after severe head injury. Clinical Rehabilitation, 14, 408416. doi:10.1191/0269215500cr326oa.

Stender, J., Gosseries, O., Bruno, M. A., Charland-Verville, V., Vanhandenhuyse, A., Demertzi, A., et al. (2014). Diagnostic precision of PET imaging and functional MRI in disorders of consciousness: a clinical validation study. Lancet, 384, 514-522 10.1016/ S0140-6736(14)60042-8. 
Stender, J., Mortensen, K. N., Thibaut, A., Darkner, S., Laureys, S., Gjedde, A., et al. (2016). The minimal energetic requirement of sustained awareness after brain injury. Current Biology, 26, 1494 1499. doi:10.1016/j.cub.2016.04.024.

Stokes, V., Gunn, S., Schouwenaars, K., \& Badwan, D. (2016). Neurobehavioural assessment and diagnosis in disorders of consciousness: a preliminary study of the sensory tool to assess responsiveness (STAR). Neuropsychological Rehabilitation. doi:10.1080/ 09602011.2016.1214604.

Sullivan, E. G., Guernon, A., Blabas, B., Herrold, A. A., \& Pape, T. L. (2017). Familiar auditory sensory training in chronic traumatic brain injury: a case study. Disability and Rehabilitation. doi:10.1080/ 09638288.2016.1277403.

Thibaut, A., Bruno, M. A., Ledoux, D., Demertzi, A., \& Laureys, S. (2014). TDCS in patients with disorders of consciousness: shamcontrolled randomized double-blind study. Neurology, 82, 1112 1118.

Thibaut, A., Wannez, S., Donneau, A. F., Chatelle, C., Gosseries, O., Bruno, M. A., et al. (2017). Controlled clinical trial of repeated prefrontal tDCS in patients with chronic minimally conscious state. Brain Injury. doi:10.1080/02699052.2016.1274776.

Vanhaudenhuyse, A., Laureys, S., \& Perrin, F. (2008). Cognitive eventrelated potentials in comatose and post-comatose states. Neurocritical Care, 8, 262-270. doi:10.1007/s12028-007-9016-0.

Vul, E., \& Pashler, H. (2012). Voodoo and circularity errors. NeuroImage, 62, 945-948. doi:10.1016/j.neuroimage.2012.01.027.

Wallace, T., \& Bradshaw, A. (2011). Technologies and strategies for people with communication problems following brain injury or stroke. NeuroRehabilitation, 28, 199-209. doi:10.3233/NRE-20110649.

Wijnen, V. J., Van Boxtel, G. J., Ellander, H. J., \& De Gelder, B. (2007). Mismatch negativity predicts recovery from the vegetative state. Clinical Neurophysiology, 118, 597-605. doi:10.1016/j.clinph. 2006.11.020.

Yamamoto, T., Katayama, Y., Obuchi, T., Kobayashi, K., Oshima, H., \& Fukaya, C. (2013). Deep brain stimulation and spinal cord stimulation for vegetative state and minimally conscious state. World Neurosurgery, 80, S30.e1-S30.e9. doi:10.1016/j.wneu.2012.04. 010 . 